\title{
Podridões de colmo estão associadas à precocidade de híbridos de milho
}

\author{
Stalk rots are associated with the early maturity of hybrid corn \\ Juliano Berghetti*, Evandro Zacca Ferreira, Ricardo Trezzi Casa, Bruno Tabarelli Scheidt, Flavio \\ Chupel Martins, Mayra Juline Gonçalves
}

Universidade do Estado de Santa Catarina, Lages, SC, Brasil. *Autor para correspondência: julianoberghetti@yahoo.com.br

Submissão: 16/01/2020 / Aceite: 29/07/2020

\begin{abstract}
RESUMO
As podridões de colmo do milho são responsáveis por significativas reduções em rendimento de grãos. 0 objetivo deste estudo foi avaliar a relação existente entre a incidência de podridões de colmo e o ciclo de seis híbridos de milho. O experimento foi conduzido a campo, semeados no mês de outubro nas safras 2012/2013 e 2013/2014 utilizando-se 70.000 sementes ha $^{-1}$ dos híbridos comerciais P32R22 YHR e AG9045 VT PRO (superprecoces) e P30F53 Hx, DKB250 VT PRO2, AS1656 VT PRO2 e AG8025 VT PRO (precoces). O delineamento utilizado foi de blocos casualizados com quatro repetições avaliando-se, em cada parcela cinco metros lineares. A incidência de podridões foi determinada pela presença de descoloração e menor resistência do colmo. Espigas provenientes de plantas sadias e doentes foram trilhadas separadamente para determinação do dano percentual. Danos ocasionados por podridões de colmo, em função da severidade da doença podem ser variáveis em função dos híbridos, mesmo com características semelhantes de ciclo. Os fungos detectados nos colmos foram Stenocarpella sp., Colletotrichum graminicola, Fusarium graminearum e F. verticillioides. Todos os híbridos avaliados expressaram sintomas de podridão de colmo demonstrando não haver resistência, mas sim, apenas diferentes graus de suscetibilidade entre os materiais testados. O híbrido AG8025 VT PRO demonstrou ser o menos suscetível a podridões de colmo. Os híbridos superprecoces P32R22 YHR e AG9045 VT PRO apresentaram maior incidência do que híbridos de ciclos precoces, indicando que a maior precocidade está associada à maior suscetibilidade a podridões de colmo.
\end{abstract}

PALAVRAS-CHAVE: Zea mays, Colletotrichum graminicola, Fusarium sp., Stenocarpella sp., genótipos.

\begin{abstract}
Stalk rots of corn are responsible for significant decreases in grain yield. The aim of this study was to examine the relationship between the incidence of stalk rots and the maturity cycle of six corn hybrids. The experiment was conducted in the field, where 70,000 seeds ha ${ }^{-1}$ of the commercial hybrids P32R22 YHR and AG9045 VT PRO (super early) and P30F53 Hx, DKB250 VT PRO2, AS1656 VT PRO2, and AG8025 VT PRO (early) were sown in October in the 2012/2013 and 2013/2014 crop years. A randomized block design with four replications was applied, and five linear meters were evaluated in each plot. The incidence of stalk rot was determined by the presence of discoloration and lower stalk resistance. Ears from healthy and infected plants were separately screened to determine the percentage loss. Losses caused by stalk rot due to the severity of the disease may vary depending on the hybrid, even if their maturity cycles have similar characteristics. The fungi detected in the stalks were Stenocarpella sp., Colletotrichum graminicola, Fusarium graminearum, and $F$. verticillioides. All of the hybrids in the study exhibited symptoms of stalk rot as they showed no resistance, but different degrees of susceptibility were observed among the tested materials. The hybrid AG8025 VT PRO demonstrated the least susceptibility to stalk rots. The super early hybrids P32R22 YHR and AG9045 VT PRO had a higher incidence than early-maturity hybrids, thus indicating that faster maturity is associated with a greater susceptibility to stalk rots.
\end{abstract}

KEYWORDS: Zea mays, Colletotrichum graminicola, Fusarium sp., Stenocarpella sp., genotypes.

\section{INTRODUÇÃO}

O milho (Zea mays L.) é um dos mais importantes cereais cultivados mundialmente. Além de elevado potencial produtivo, é referência energética, sendo matéria prima fundamental na alimentação animal, 
humana e produção de biocombustível (WORDELL FILHO \& CHIARADIA 2016). É o segundo grão de maior produção, sendo o primeiro entre os cereais produzidos no Brasil, que ocupa a terceira posição entre os maiores produtores mundiais, atrás apenas dos Estados Unidos da América e China (USDA 2020).

A produtividade do milho é determinada por uma série de fatores, dentre eles a variabilidade no potencial produtivo em função da genética, efeito de elementos climáticos, condições químicas, físicas e biológicas de solo e a ocorrência de plantas daninhas, insetos e doenças (WORDELL FILHO \& CHIARADIA 2016).

As doenças no milho ocorrem em diversos órgãos da planta, compreendendo raízes, colmos, folhas e espigas. Nos colmos ocorrem as podridões de colmo (PC) que comprometem a translocação de água e nutrientes, afetando o enchimento de grãos e ocasionando tombamento de plantas ao final do ciclo (CASA et al. 2007).

Os fungos com frequência associados à PC são Colletotrichum graminicola (Ces.) G.V. Wils. (antracnose), Stenocarpella macrospora Earle e S. maydis Berk. (diplodia), Fusarium graminearum Schewabe (giberela), F. verticillioides (Sacc.) Nirenberg (fusariose) (RIBEIRO et al. 2005) e Macrophomina phaseolina Tassil (macrofomina) (CASELA et al. 2006).

Como alternativas de controle para estes fungos são indicados a utilização de genótipos resistentes (MATIELLO et al. 2013) e a rotação e sucessão de culturas com espécies não hospedeiras (DENTI \& REIS 2001). Espécies não hospedeiras reduzem a quantidade de inóculo nas áreas de cultivo tendo em vista que os fungos causadores de PC são necrotróficos, capazes de sobreviver em restos culturais hospedeiros.

Entre híbridos de diferentes ciclos e conformação genética pode haver variação no comportamento morfofisiológico, afetando diretamente aspectos epidemiológicos de fitopatógenos. O objetivo deste trabalho foi avaliar o efeito de ciclos contrastante na suscetibilidade de híbridos de milho à podridão de colmo, quantificando a incidência, rendimento de grãos e danos.

\section{MATERIAL E MÉTODOS}

O estudo foi conduzido nas safras 2012/2013 e 2013/2014 em condições de campo sob coordenadas geográficas de $28^{\circ} 18^{\prime} 51^{\prime \prime}$ de latitude Sul e 5110'54" de longitude Oeste e altitude de 937 metros, no município de Muitos Capões, Nordeste do estado do Rio Grande do Sul, RS. O solo da região é classificado como Latossolo Bruno alumínico de acordo com o Sistema Brasileiro de Classificação de Solos. O clima é do tipo Cfb de acordo com Köppen e Geiger, com média anual de $16,2{ }^{\circ} \mathrm{C}$ de temperatura e $1775 \mathrm{~mm}$ de pluviosidade.

A semeadura do milho foi realizada mecanicamente, em área de rotação com feijão e em sucessão à aveia preta nas duas safras agrícolas. As áreas utilizadas localizavam-se à distância superior a um raio de 1 $\mathrm{km}$ de lavouras onde se cultivou milho no verão anterior a implantação do experimento. Foram utilizados os híbridos comerciais P30F53 Hx, P32R22 YHR, DKB250 VT PRO2, AS1656 VT PRO 2, AG8025 VT PRO e AG9045 VT PRO (Tabela 1), selecionados por sua ampla área de cultivo na região dos Campos de Cima da Serra.

Tabela 1. Características dos híbridos cultivados nos experimentos de Muitos Capões, RS, safras 2012/2013 e 2013/2014.

Table 1. Characteristics of the hybrids cultivated in the experiments in Muitos Capões, RS, crop years 2012/2013 and 2013/2014.

\begin{tabular}{lllll}
\hline Híbrido & Ciclo & Empresa & Tipo & Grão \\
\hline AS1656 VT PRO2 & Precoce & Agroeste & HS* & Semi duro \\
DKB250 VT PRO2 & Precoce & Dekalb & HS & Semi dentado \\
P30F53 Hx & Precoce & Pioneer & HS & Semi duro \\
P32R22 YHR & Superprecoce & Pioneer & HS & Semi dentado \\
AG8025 VT PRO & Precoce & Agroceres & HS & Semi duro \\
AG9045 VT PRO & Superprecoce & Agroceres & HS & Semi duro \\
\hline
\end{tabular}

*HS: híbrido simples.

As unidades experimentais de $125 \mathrm{~m}^{2}$ (25 m de comprimento $\times 5 \mathrm{~m}$ de largura) compreendiam 10 linhas de semeadura espaçadas em $0,5 \mathrm{~m}$. O delineamento experimental foi conduzido em blocos casualizados, com quatro repetições. 
Na safra 2012/2013, a semeadura foi realizada dia 25 de outubro de 2012, e na safra posterior em 12 de outubro, ambas com densidade equivalente a 72.000 sementes por hectare. A adubação de base na primeira safra foi de $300 \mathrm{~kg} \mathrm{ha}^{-1}$ da formulação 14-33-00, e $100 \mathrm{~kg} \mathrm{ha}^{-1}$ de $\mathrm{KCl}$, e na segunda safra, de 170 $\mathrm{kg} \mathrm{ha}^{-1}$ da formulação18-46-00 e $100 \mathrm{~kg} \mathrm{ha}^{-1}$ de KCl. A adubação nitrogenada de cobertura foi realizada no estádio V3, com ureia (45\% de N), na dose de $300 \mathrm{~kg} \mathrm{ha}^{-1}$. Dados climáticos das safras 2012/2013 (Figura 1a) e 2013/2014 (Figura 1b) foram obtidos pela plataforma online da estação automática do INMET do município de Vacaria (temperaturas) e leitura pluviométrica diária no local do experimento (chuvas).

a) Safra 2012/13

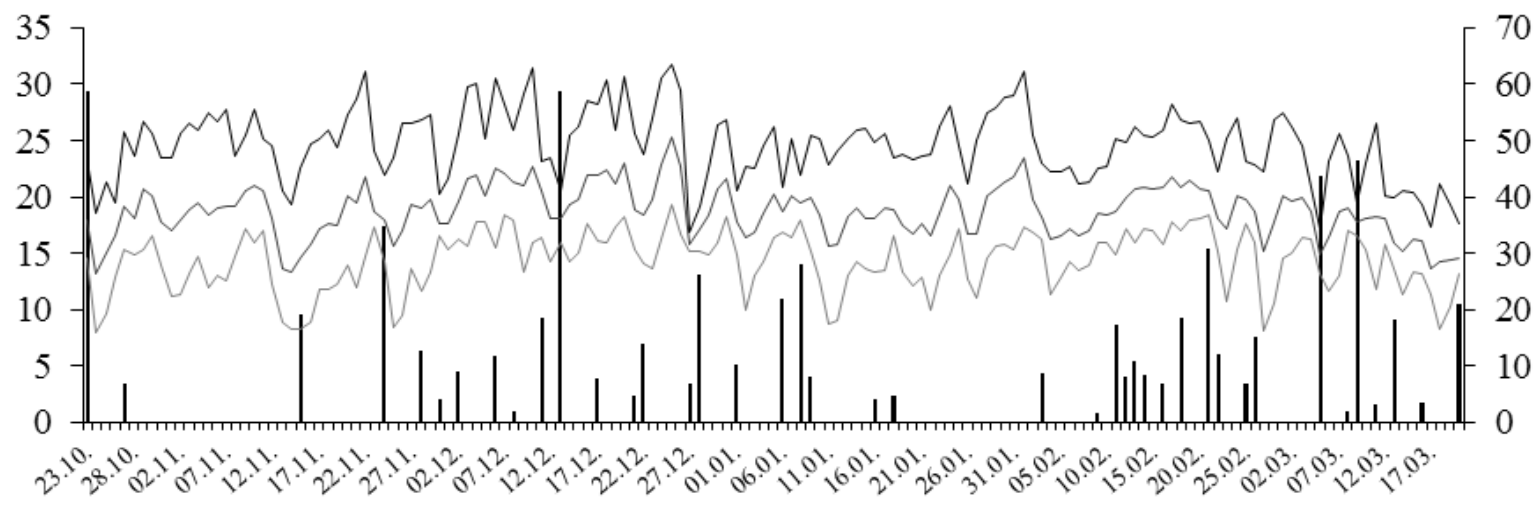

b)

Safra 2013/14

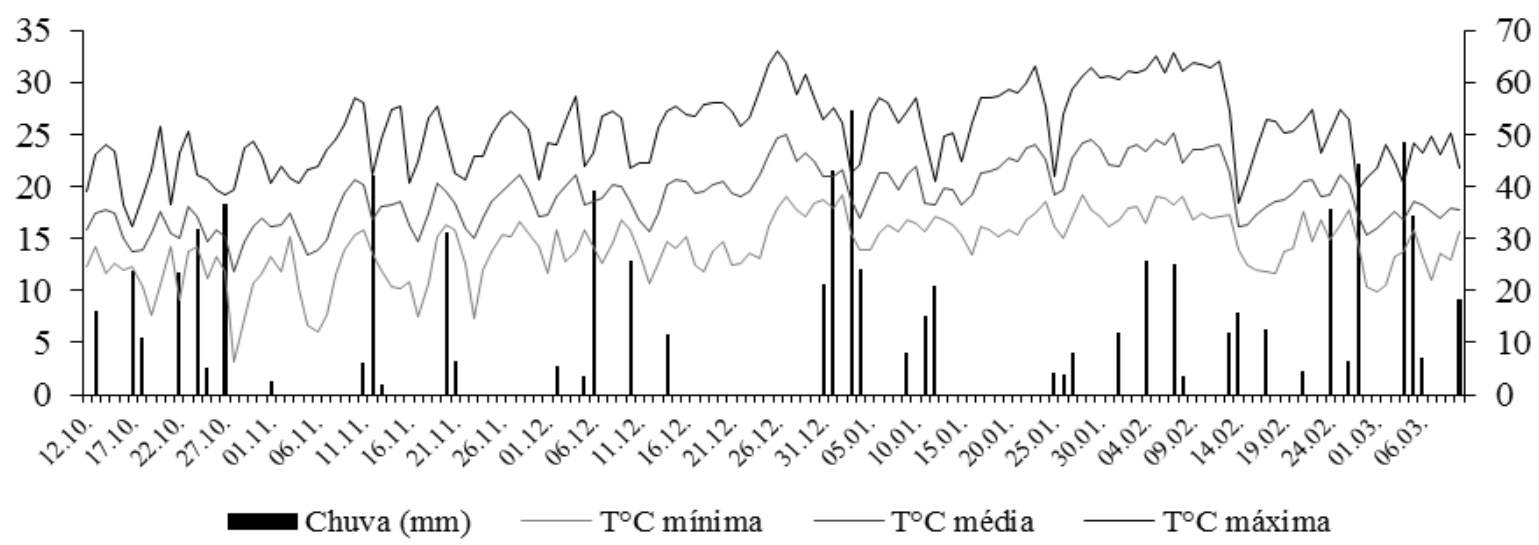

Figura 1. Dados climáticos de chuva (sessão à direita em $\mathrm{mm}$ ) e temperaturas mínima, média e máxima (sessão esquerda em ${ }^{\circ} \mathrm{C}$ ) diária durante o período de condução do experimento nas safras de 2012/2013 e 2013/2014 em Vacaria, RS.

Figure 1. Climate data on precipitation (session on the right in $\mathrm{mm}$ ) and minimum, average, and maximum daily temperatures (session on the left in ${ }^{\circ} \mathrm{C}$ ) during the experimental period in the 2012/2013 and 2013/2014 crop years in Vacaria, $R S$.

Nas duas safras o controle de plantas daninhas foi realizado com pulverização em estádio V4, utilizando-se dos herbicidas atrazina + simazina + tembotriona + estér metílico de óleo de soja, nas doses de $1000+1000+100,8+576$ g i.a. ha ${ }^{-1}$, respectivamente. Não foram realizadas aplicações de fungicidas.

A incidência de PC foi quantificada na colheita, quando cada híbrido apresentava teor de umidade médio de grãos em $16 \% \pm 1 \%$, determinado pela trilha de grãos em linhas de bordadura de cada parcela e adição destes a equipamento específico de teste previamente calibrado. Avaliaram-se cinco metros lineares em cada parcela. Seguiu-se metodologia proposta por REIS et al. (1998), identificando as plantas sintomáticas após remoção das folhas da base do colmo de todas as plantas. Considerou-se sintomática a planta que apresentou descoloração da base do colmo e/ou aquela com menor resistência à pressão entre os dedos polegar e indicador. Da base do colmo sintomático foram retirados fragmentos, encaminhados ao laboratório para isolamento em meio de cultura para confirmação da presença de fungos. Os fragmentos foram desinfestados em hipoclorito de sódio (1\%) por três minutos, sendo posteriormente lavados em água 
destilada autoclavada e acondicionados em placas de Petri contendo meio de cultura de batata-sacaroseágar. As placas foram alocadas em câmara de crescimento em temperatura de $23^{\circ} \mathrm{C} \pm 1{ }^{\circ} \mathrm{C}$ e fotoperíodo de 12 horas durante sete dias. A identificação foi realizada de forma visual pelas características de coloração e crescimento de colônias de fungos tradicionalmente causadores de PC. Também foram utilizadas lâminas de microscopia para verificação das estruturas fúngicas, como esporos sexuados e assexuados e eventual formação de estruturas de resistência, conforme descritas na literatura (BARNETT \& HUNTER 1998, WHITE 1999). Em caso de ausência de crescimento de colônias a planta foi considerada sadia. Os dados foram expressos em incidência de PC.

O rendimento de grãos foi determinado realizando-se a colheita manual das espigas correspondentes à unidade amostral de cada parcela. As espigas provenientes de plantas sadias e doentes foram trilhadas separadamente e os grãos secos em estufa até a obtenção de peso constante, sendo os valores convertidos em kg ha ${ }^{-1}$ na umidade padrão de $13 \%$.

Os procedimentos foram: pesagem dos grãos das espigas provenientes de plantas sadias e doentes, separadamente, e determinação do dano percentual pela diferença entre rendimento real e potencial, onde o rendimento potencial foi determinado pela divisão do peso total de grãos de plantas sadias pelo número de plantas sadias e posterior multiplicação pelo número total de plantas avaliadas; e o cálculo do rendimento real determinado através da soma do peso dos grãos das espigas de plantas com colmos sadios e doentes (REIS et al. 1998). Os dados obtidos para incidência de PC, dano e rendimento de grãos de milho foram submetidos à análise de variância e, quando significativos, efetuou-se comparação das médias por meio do teste Scott-Knott, em nível de significância de $5 \%(p<0,05)$ utilizando o software SAS 9.1 (SAS Institute, Cary, NC, USA).

\section{RESULTADOS E DISCUSSÃO}

Houve interação significativa entre híbridos e safras e, portanto, os dados são discutidos separadamente. Em comum às safras, os híbridos superprecoces P32R22 YHR e AG9045 VT PRO apresentaram maior incidência de PC em relação aos demais de ciclos precoces (Figura 2a), indicando a existência de relação entre a precocidade dos híbridos e a suscetibilidade do colmo a podridões. Na safra 2012/2013 a incidência de $100 \%$ e $97 \%$ para os respectivos híbridos impossibilitaram o cálculo de danos referente ao percentual de redução do rendimento de grãos (Figuras $2 a$ e $2 b$ ) devido ao insuficiente número de plantas sadias. Na safra $2013 / 2014$ os percentuais de incidência diminuíram para $73 \%$ e $66 \%$, desta vez, embora ainda tenham mantido as maiores incidências de PC, possibilitou-se a determinação dos danos pela redução percentual de rendimento.

As infecções fúngicas no colmo são favorecidas por prolongados períodos de molhamento. Nota-se que na safra 2012/2013 houve chuvas frequentes, e uma maior concentração destas no período entre 10 e 25 de fevereiro (Figura 1), onde as plantas encontravam-se em fase de enchimento de grãos. A indisponibilidade de radiação solar compromete a eficiência fotossintética, que reduzida, pode forçar as plantas a utilizar de drenos, principalmente os armazenados no colmo, desta forma, tornando-os mais frágeis e propensos a infecção (BERGHETTI et al. 2019). O final do ciclo tende a ser a fase mais afetada por fungos causadores de PC, na qual são evidentes os sintomas de infecção (WORDELL FILHO \& CHIARADIA 2016). Colletotrichum graminicola é um fungo beneficiado por condições de baixa luminosidade (SCHALL et al. 1980) e está entre os fungos predominantes em PC de milho no Sul do Brasil (DENTI \& REIS 2003).

Embora os híbridos superprecoces tenham apresentado proximidade nos valores de incidência, observou-se que o dano percentual maior ocorreu para o híbrido AG9045 VT PRO com 22,4\% em relação a 6,6\% de P32R22 YHR. O híbrido P32R22 YHR demonstra maior tolerância à PC em relação ao híbrido AG9045 VT PRO. Esse comportamento indica que os danos ocasionados por PC podem ser variáveis em função dos híbridos, mesmo com características semelhantes de ciclo. Há a hipótese de que os fungos associados apresentaram diferentes graus de severidade de infecção em função dos híbridos avaliados, no entanto, esta variável não foi mensurada. A elevada incidência não garante por si só a redução no rendimento de grãos. Já o elevado percentual de severidade está atrelado à área de colonização do colmo pelo patógeno, podendo envolver maior competição por drenos. Além disso, os genótipos respondem diferentemente em relação ao seu grau de tolerância, podendo mesmo infectados não apresentar danos.

A maior precocidade de um híbrido faz com que o seu pendão floral se desenvolva mais rapidamente, o que reduz o número de folhas e consequentemente sua área foliar em detrimento da floração (FANCELLI 2000, SANGOI 2001). Híbridos tardios, por sua vez, apresentam maior período vegetando (SANGOI 2001). Quando ocorre reduzida área foliar há uma tendência de aumento na contribuição do colmo no suprimento 
de fotoassimilados ao enchimento de grãos (SANGOI et al. 2010). Este fato pode ocasionar fragilidade dos tecidos do colmo e maior suscetibilidade aos fungos causadores de podridões, neste caso, agravando-se em híbridos de maior precocidade (BERGHETTI et al. 2019).

a)

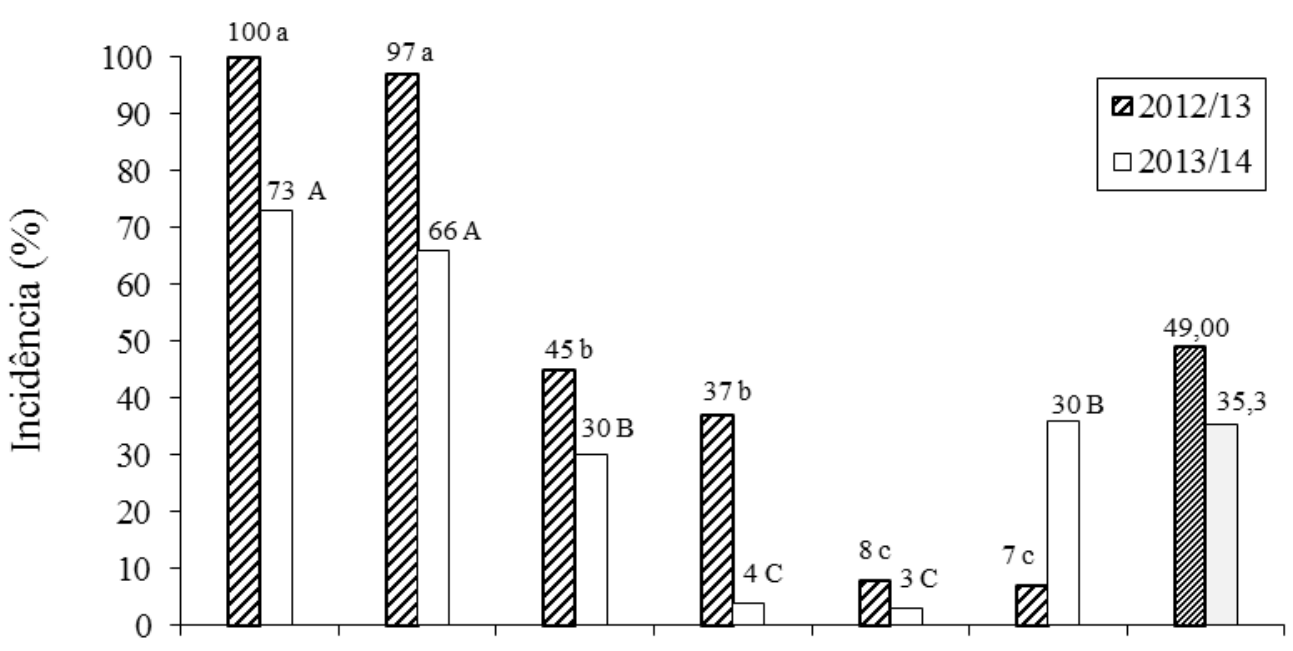

b)

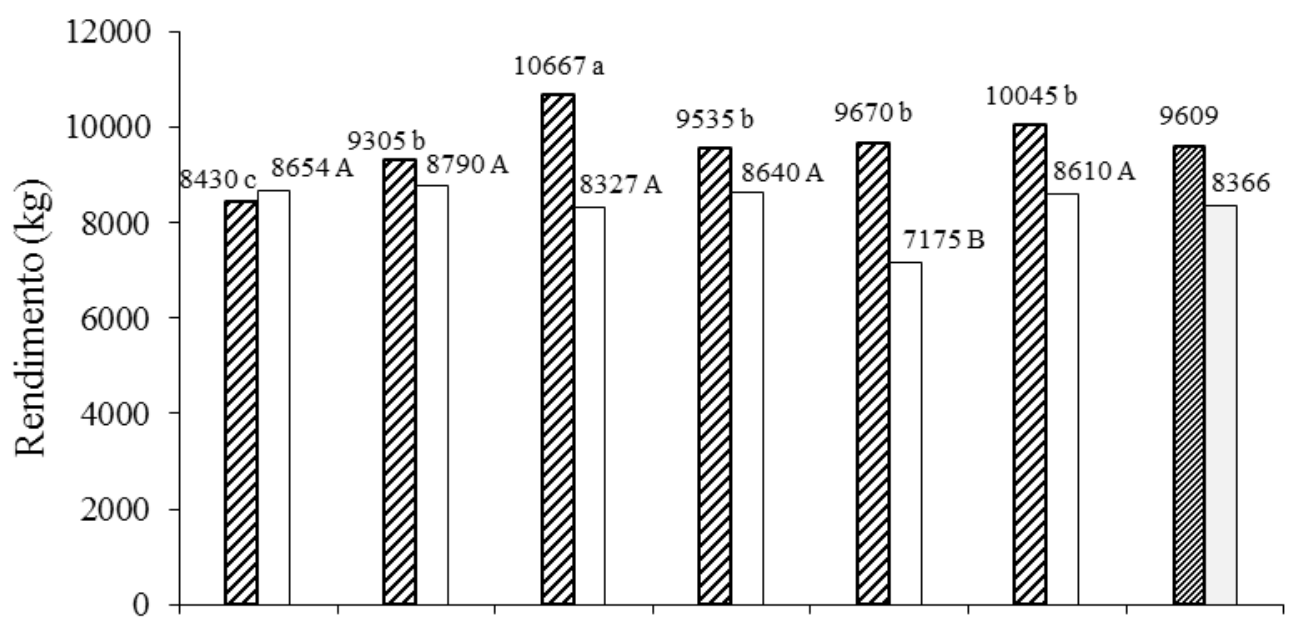

c)

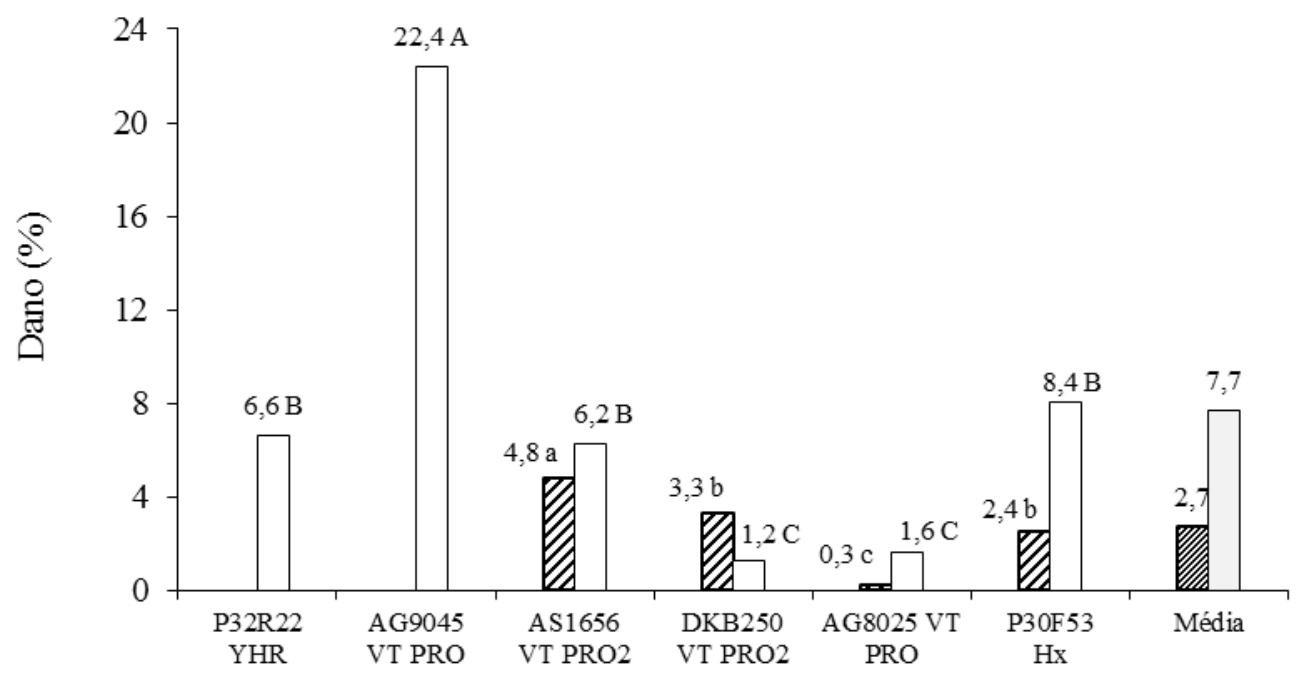

Figura 2. Incidência de podridão de colmo (a); rendimento de grãos (b) e dano percentual (c) em híbridos de milho cultivados em Muitos Capões, RS, safras 2012/2013 e 2013/2014.

Figure 2. Incidence of stalk rot (a), grain yield (b), and percentage loss (c) in corn hybrids cultivated in Muitos Capões, RS, crop years 2012/2013 and 2013/2014. 
Entre os híbridos precoces, AS1656 VT PRO2 e DKB250 VT PRO2 demonstraram ser os mais suscetíveis à PC na safra 2012/2013, não diferindo estatisticamente do híbrido P30F53 Hx na safra 2013/2014, porém com maior incidência em relação à AG8025 VT PRO em ambas as safras (Figura 1a). O híbrido AG8025 VT PRO demonstrou ser o menos suscetível à PC.

Os híbridos precoces mantiveram uma relação alinhada entre a incidência de PC e o percentual de danos, onde os maiores percentuais de incidência resultaram também em maiores danos. Isso ocorre, pois plantas infectadas tendem a apresentar um menor peso de grãos, principalmente onde não ocorre tolerância ou elevado grau de resistência do genótipo aos patógenos.

Os fungos detectados na patologia de colmos sintomáticos foram, C. graminicola, Stenocarpella sp., F. graminearum e F. verticillioides. Apesar de não determinada a prevalência dos fungos, trabalhos como DENTI \& REIS (2003) e BERGHETTI et al. (2019) demonstram predomínio de Coletotrichum graminicola em relação a fungos do gênero Fusarium e Stenocarpella causando PC no Sul do Brasil. Todos os híbridos avaliados expressaram sintomas de PC, o que indica graus de suscetibilidade dos híbridos ao complexo de fungos associados. Em estudo conduzido por COSTA et al. (2010) também foram observadas variações entre os genótipos em diferentes épocas de semeadura quanto à incidência de $C$. graminicola no colmo, no entanto, nenhum híbrido pôde ser considerado como resistente ao patógeno. Os autores relacionaram a PC aos genótipos e as condições ambientais das diferentes safras avaliadas.

É importante salientar que mesmo com dano de 22,4\% o híbrido AG9045 VT PRO com $9.305 \mathrm{~kg} \mathrm{ha}^{-1}$ de grãos produzidos manteve produtividade similar aos demais híbridos, ficando abaixo apenas de AS1656 VT PRO2 com $10.667 \mathrm{~kg} \mathrm{ha}^{-1}$ na safra 2012/2013. Na safra 2013/2014 o híbrido AG9045 VT PRO foi superior em produtividade ao híbrido AG8025 VT PRO (menor suscetibilidade a PC), e estatisticamente igual aos demais. Esta ocorrência pode ser explicada pela linha seguida pelo melhoramento genético onde o potencial produtivo e menor ciclo de híbridos são priorizados em relação aos aspectos fitossanitários.

Em geral híbridos de maior precocidade e de elevado potencial produtivo tendem a ser mais suscetíveis a doenças. Isso ocorre, pois, estas características são poligênicas e possuem correlação negativa de difícil seleção conjunta (MENDONÇA et al. 2016). Características de híbridos, como baixa relação entre fonte e dreno estão associadas às maiores severidades de PC, estas que são detectadas com maior frequência em híbridos de maior precocidade, onde a sua menor área foliar acarreta em maior mobilização de carboidratos do colmo para as espigas em detrimento do enchimento de grãos, o que torna seus tecidos frágeis e suscetíveis a infecções (BLUM et al. 2003). Avaliando dois híbridos, AG9025 PRO3 superprecoce e 30F53 VYH precoce, BERGHETTI et al. (2019) constataram que o híbrido de maior precocidade apresentou maior incidência de PC, também observaram que o incremento de doses de nitrogênio manteve a estabilidade do colmo e reduziu a incidência de PC, provavelmente pelo aumento da capacidade fotossintética, exigindo uma menor mobilização de açúcares do colmo para o enchimento de grãos.

\section{CONCLUSÃO}

Híbridos de maior precocidade são mais propensos a infecções de fungos causadores de podridões de colmo, embora não haja um efeito pronunciado na redução do rendimento de grãos.

O híbrido AG8025 VT PRO apresenta menor suscetibilidade às podridões de colmo em comparação aos demais híbridos de ciclos precoces e superprecoces avaliados.

\section{REFERÊNCIAS}

BARNET HL \& HUNTER BB 1998. Illustrated genera of imperfect fungi. 4.ed. St. Paul: The american Phytopathological Society. 218p.

BERGHETTI JB et al. 2019. Incidence of stalk rots in corn hybrids influenced by sowing time and nitrogen rates. Bragantia 78: 371-378.

BLUM LEB et al. 2003. Desfolha, população de plantas e precocidade do milho afetam a incidência e a severidade de podridões de colmo. Ciência Rural 33: 805-811.

CASA RT et al. 2007. Incidência de podridões de colmo, grãos ardidos e rendimento de grãos em híbridos de milho submetidos ao aumento na densidade de plantas. Summa Phytopathologica 33: 353-357.

CASELA CR et al. 2006. Doenças na cultura do milho. Sete Lagoas: EMBRAPA, 14p. (Circular técnica).

COSTA RV et al. 2010. Incidência de Colletotrichum graminicola em colmos de genótipos de milho. Summa Phytopathologica 36: 122-128.

DENTI EA \& REIS EM. 2001. Efeito da rotação de culturas, da monocultura e da densidade de plantas na incidência das podridões da base do colmo e no rendimento de grãos de milho. Fitopatologia Brasileira 26: 635-639.

DENTI EA \& REIS EM. 2003. Levantamento de fungos associados às podridões de colmo e quantificação de danos em lavouras de milho do Planalto Médio Gaúcho (RS) e dos campos gerais do Paraná. Fitopatologia Brasileira 28: 585- 
590.

FANCELLI AL. 2000. Fisiologia da produção e aspectos básicos de manejo para altos rendimentos. In: SANDINI I \& FANCELLI AL. Milho: estratégias de manejo para a região sul. Guarapuava: Fundação de Pesquisa Agropecuária. p.103-116.

MATIELLO RR et al. 2013. Comparison of yield damage of tropical maize hybrids caused by anthracnose stalk rot. Tropical Plant Pathology 38: 128-132.

MENDONÇA LF et al. 2016. Accuracy and simultaneous selection gains for grain yield and earliness in tropical maize lines. Maydica 61: 1-7.

REIS EM et al. 1998. Método para quantificar os danos no rendimento de grãos causados pelas podridões da base do colmo do milho. Fitopatologia Brasileira 23: 300.

RIBEIRO NA et al. 2005. Incidência de podridões de Colmo, grãos ardidos e produtividade de grãos de genótipos de milho em diferentes sistemas de manejo. Ciência Rural 35: 1003-1009.

SANGOI L. 2001. Understanding plant density effects on maize growth and development: an important issue to maximize grain yield. Ciência Rural 31: 159-168.

SANGOI L et al. 2010. Ecofisiologia da cultura do milho para altos rendimentos. Lages: Graphel. 87p.

SCHALL RA et al. 1980. Influence of light on maize anthracnose in the greenhouse. Phytopathology 70: 1023-1026.

USDA. 2020. United States Department of Agriculture. Foreign Agricultural Service: Corn. Disponível em: https://www.fas.usda.gov/data/search?f\%5B0\%5D=field_commodities\%3A 14. Acesso em: 20 abr. 2020.

WHITE DG 1999. Compendium of corn diseases. St. Paul: APS Press. 78p.

WORDELL FILHO JA \& CHIARADIA LA 2016. (Orgs.). A cultura do milho em Santa Catarina. 3.ed. Florianópolis: EPAGRI. 400p. 